Theoretical

and Applied

Climatology

(C) by Springer-Verlag 1988

551.510 .52

\footnotetext{
${ }^{1}$ Institute of Atmospheric Physics, ${ }^{2}$ Institute for Optoelectronics, German Aerospace Research Establishment (DFVLR) Oberpfaffenhofen, Federal Republic of Germany
}

\title{
An Intercomparison of Meteorological Data Taken by Aircraft, Radiosondes and a Laser-Doppler-Anemometer
}

\author{
K. P. Hoinka ${ }^{1}$, H. P. Fimpel ${ }^{1}$, and F. Köpp ${ }^{2}$
}

With 8 Figures

Received April 10, 1987

Revised October 8, 1987

\begin{abstract}
Summary
This paper describes an intercomparison experiment between airborne measurement systems, radiosondes and a LaserDoppler-Anemometer (LDA). The aircraft are a Falcon, a Queenair and three motorized sailplanes; the radiosonde is a GRAW-type sonde. Overall we find a $r m s$-difference in temperature of between $-0.66 \mathrm{~K}$ and $+0.52 \mathrm{~K}$. The $r m s-$ differences for the dew-points are between $-1.2 \mathrm{~K}$ and $+1.57 \mathrm{~K}$. The mean $r m s$-differences between the sonde, the sensors of the Falcon and the LDA are between $-0.92 \mathrm{~m} \mathrm{~s}^{-1}$ and $+0.63 \mathrm{~m} \mathrm{~s}^{-1}$ for both components of the wind. The magnitude of the $r m s$-differences are similar to the accuracies of the sensors indicating the high quality of the data.
\end{abstract}

\section{Zusammenfassung}

Ein Vergleich meteorologischer Daten von Flugzeugen, Radiosonden und einem Laser-Doppler-Anemometer

Die Arbeit beschreibt ein Vergleichsexperiment zwischen Daten, gewonnen mit Hilfe von Flugzeugen, Radiosonden und einem Laser-Doppler-Anemometer (LDA). Bei den Flugzeugen handelt es sich um eine Falcon, eine Queenair und drei Motorsegler; die Radiosonde ist eine GRAW-Sonde. Die mittleren quadratischen Abweichungen der Temperaturwerte liegen zwischen $-0.66 \mathrm{~K}$ und $+0.52 \mathrm{~K}$; für den Taupunkt ist dieser Bereich zwischen $-1.2 \mathrm{~K}$ und $+1.57 \mathrm{~K}$. Für beide Windkomponenten liegen die mittleren quadratischen $\mathrm{Ab}$ weichungen zwischen der Sonde, den Sensoren der Falcon und dem LDA im Bereich von $-0.92 \mathrm{~m} \mathrm{~s}^{-1}$ und $+0.63 \mathrm{~m} \mathrm{~s}^{-1}$. Die mittleren quadratischen Abweichungen sind von gleicher Größenordnung wie die absoluten Fehler der Sensoren, was die hohe Qualität der Daten bestätigt.

\section{Introduction}

In field experiments coordinated series of measurements are performed by various systems in order to obtain data sets as complete as possible. To relate these data sets to each other, it is necessary to know the absolute error (accuracy) and the relative error (resolution) of each measurement system, as well as the differences between them. These differences can be obtained by performing an intercomparison experiment.

Intercomparison flights were made during ALPEX to compare the measuring equipment of the aircraft Falcon with that of other aircraft (Fimpel and Richner, 1986). The results show that the differences in temperature, humidity and wind taken by the sensors of these aircraft are within the accuracy of each measurement system. Hauf et al. (1988) describe a comparison of data taken by the Falcon with sounding data obtained by radiosondes. In Switzerland various radiosondes 
were compared by Phillips et al. (1980) and Phillips and Richner (1983). Further comparisons were made between sondes and a Laser-Doppler-Anemometer (LDA) (Köpp et al., 1984). However, to our knowledge no comparison between measurement systems of several aircraft, sondes and LDA has yet been made. For low levels, up to $300 \mathrm{~m}$ above ground, a comparison was performed in 1979 (Kaimal et al., 1980). The one presented here was done between $300 \mathrm{~m}$ and $2300 \mathrm{~m}$ above ground.

This paper describes the execution and the results of an intercomparison experiment which was performed on 27. June 1986 during the DFVLRfront-experiment. A twin-engine jet Falcon, a Queenair and three motorized sailplanes collected temperature and humidity data. The Falcon is additionally equipped with a sensor to measure the wind vector. Radiosondes were launched to get vertical soundings. Finally, low-level wind data were gathered continuously by a Laser-DopplerAnemometer. The purpose of the comparison is to calibrate all systems, so they can be used for coordinated measurements in frontal zones close to the Alps. The results of the comparison experiment are important especially to the frontal experiment itself, and provide also information for comparison experiments elsewhere.

In section two we briefly discuss the synoptic situation. In section three we summarize the characteristics of the sensors of the various systems, and the fourth section describes the experimental design. The fifth section discusses the treatment of the data, and the final section reports the results of the comparison of the temperature, humidity and wind measurements.

\section{Synoptic Situation}

The comparison was performed on 27 June 1986 as part of a front experiment coordinated by the DFVLR. The large-scale weather patterns are characterized by an omega-type-structure, with a ridge of high pressure over Europe flanked by troughs over the eastern Atlantic Ocean and over eastern Europe. The pressure gradients in the Alpine area are weak, with a surface flow from the east at about $5 \mathrm{~m} \mathrm{~s}^{-1}$. All measurements are made early in the morning, between 0700 and 0800 MESZ (0500 and 0600 GMT), before convective processes start to dominate the flow. Figure 1
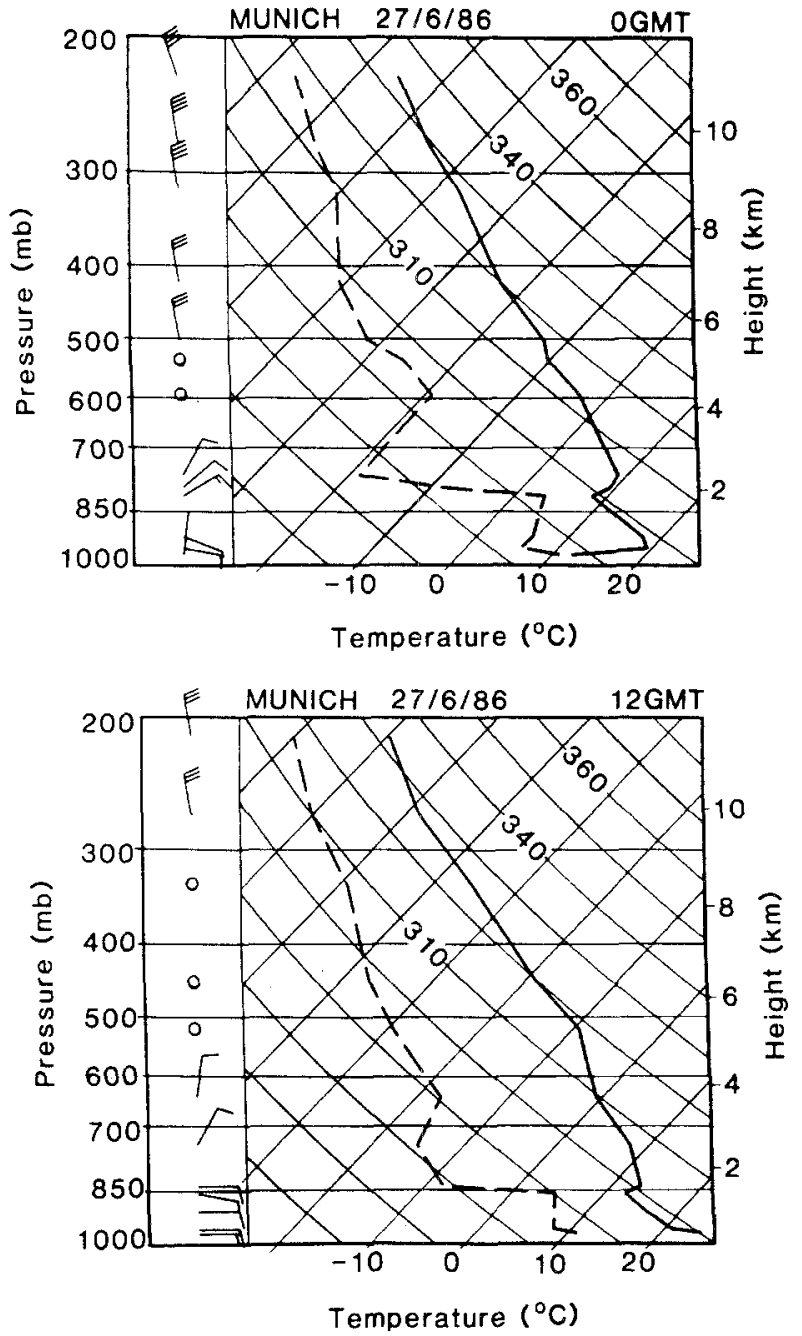

Fig. 1. Radiosonde profiles at Munich on 27 June 1986, 0000 and 1200 GMT. The oblique axes show the potential temperatures in $\mathrm{K}$. The wind barbs are given using standard notation

shows the radiosonde observations from Munich at 0000 and 1200 GMT, with weak easterlies at low levels and with a calm mid-troposphere. At about $1500 \mathrm{~m}$ an inversion is apparent; this inversion is also present in the night but is found higher at $2000 \mathrm{~m}$. During the night there is also a surface based inversion with a temperature difference of $9 \mathrm{~K}$. However, the basic profile is the same.

\section{Sensors}

Five different aircraft, a twin-engine jet Falcon, a Queenair and three motorized sailplanes were available. All aircraft sensors are able to record temperature, humidity and pressure and the Fal- 
Table 1. Instrumentation of the Aircraft Falcon, Queenair, Motorized Sailplanes, the GRAW-Sonde and the LDA

\begin{tabular}{|c|c|c|c|}
\hline Parameter & Sensor & Accuracy & Resolution \\
\hline \multicolumn{4}{|l|}{ Falcon } \\
\hline Wind: $u, v, w$ & $\begin{array}{l}\text { "Five-hole" probe and } \\
\text { inertial navigation system }\end{array}$ & $\begin{array}{l}1.5 \mathrm{~m} / \mathrm{s} \\
0.5 \mathrm{~m} / \mathrm{s}\end{array}$ & $\begin{array}{l}0.1 \mathrm{~m} / \mathrm{s}(\mathrm{u}, \mathrm{v}) \\
0.1 \mathrm{~m} / \mathrm{s}(\mathrm{w})\end{array}$ \\
\hline Temperature & Open-wire total air temperature probe & $0.5 \mathrm{~K}$ & $0.05 \mathrm{~K}$ \\
\hline Temperature & Total air temperature probe & $0.5 \mathrm{~K}$ & $0.05 \mathrm{~K}$ \\
\hline Rel. Humidity & Humicap & $5.0 \%$ & $0.2 \%$ \\
\hline Pressure & Pitot static probe & $0.25 \mathrm{mbar}$ & $0.25 \mathrm{mbar}$ \\
\hline Latitude/Longitude & Inertial navigation system & depends on flight time & $0.5^{\prime \prime}$ \\
\hline \multicolumn{4}{|l|}{ Queenair } \\
\hline Temperature & PT-100 & $0.2 \mathrm{~K}$ & $0.02 \mathrm{~K}$ \\
\hline Dew-point & TP 3-S & $0.2 \mathrm{~K}$ & $0.1 \mathrm{~K}$ \\
\hline Pressure & Static probe & $1.0 \mathrm{mbar}$ & $0.2 \mathrm{mbar}$ \\
\hline \multicolumn{4}{|l|}{ Motorized sailplanes } \\
\hline Temperature & PT-100 & $0.2 \mathrm{~K}$ & $0.02 \mathrm{~K}$ \\
\hline Rel. Humidity & Humicap & $5.0 \%$ & $0.2 \%$ \\
\hline Pressure & Static probe & $2.0 \mathrm{mbar}$ & $0.5 \mathrm{mbar}$ \\
\hline \multicolumn{4}{|l|}{ GRAW-77Q sonde } \\
\hline Temperature & Bead thermistor & $0.4 \mathrm{~K}$ & $0.1 \mathrm{~K}$ \\
\hline Wet-bulb temperature & Bead thermistor & $0.4 \mathrm{~K}$ & $0.2 \mathrm{~K}$ \\
\hline Pressure & Aneroid capsule & $2.0 \mathrm{mbar}$ & $5.0 \mathrm{mbar}$ \\
\hline \multicolumn{4}{|c|}{ Laser-Doppler-Anemometer (LDA) } \\
\hline Wind: $u, v$ & CW Doppler Lidar & $0.2 \mathrm{~m} / \mathrm{s}$ & $0.2 \mathrm{~m} / \mathrm{s}$ \\
\hline
\end{tabular}

con is additionally equipped with a system to measure the three-dimensional wind vector. The wind is measured on this airplane as the difference between the velocity of air relative to the airplane, obtained from gust probe sensors mounted on a nose boom, and the velocity of the airplane relative to the earth from the inertial navigation system (INS). The errors of the INS and of the gust probe sensor result in an absolute error of about $1.5 \mathrm{~m} \mathrm{~s}^{-1}$ in the derived horizontal velocities. The aircraft are able to collect data up to a height of $10 \mathrm{~km}$ (Falcon), $4 \mathrm{~km}$ (Queenair) and $2 \mathrm{~km}$ (motorized sailplanes). The airborne measurement systems are described in detail elsewhere: Falcon (Meischner, 1985), Queenair (Paffrath, 1985) and motorized sailplanes (Jochum et al., 1984).

Radiosonde data are provided by "GRAW77 Q" sondes, which are lightweight weather sondes for measuring temperature, humidity and atmospheric pressure in the free atmosphere up to about 600 mbar. For the dry- and wet-bulb temperatures, bead thermistors are used. This sonde is also termed TDFS-sonde and is described by Fink et al. (1980). A similar type to our GRAW-77 Q sonde is compared with other sonde types by Phillips and Richner (1983). The horizontal wind vector is obtained by using a radar to track the sonde.

A surface-based Laser-Doppler-Anemometer (LDA) takes wind data. The LDA data consists of radial velocity values as a function of scan azimuth; the pattern is also known as a velocityazimuth-display (VAD) scan. This method is used to retrieve mean horizontal wind magnitude and direction from radial velocity data around horizontal circles centered along the vertical of the lidar scanner. The method and the instrument is described in detail by Köpp et al. (1984) and 
Schwiesow et al. (1985). Table 1 summarizes the types of the sensors, and their absolute errors (accuracy) and their relative errors (resolution).

\section{Experimental Design}

The main difficulty in comparing data from ground-based systems, aircraft and radiosondes is due to the fact that the various systems measure data at different time and space scales. A further complication comes from the fact that one compares line-averaged data obtained from an aircraft along a horizontal flight leg with vertically spaced radiosonde data and with data derived by volume averaging the meteorological quantities taken by remote sensing methods. The problem of comparing line-averaged data with vertically spaced radiosonde data is discussed in detail by Hauf et al. (1988). The problems are kept small as soon as there are horizontal homogeneous atmospheric conditions; if the averaging length over the flight leg is short enough; and if the measurements are taken during a reasonably short period of time. The experiment was designed such as to fulfill these conditions.

The comparison presented here uses data from between $300 \mathrm{~m}$ and $2300 \mathrm{~m}$ above ground, which is where most of the interesting processes in frontal zones occur. Additionally, the experimental design was created to provide optimal coverage of a timeheight section by the various measurement systems.

We made measurements at the Oberpfaffenhofen airfield, $25 \mathrm{~km}$ south-west of Munich. The

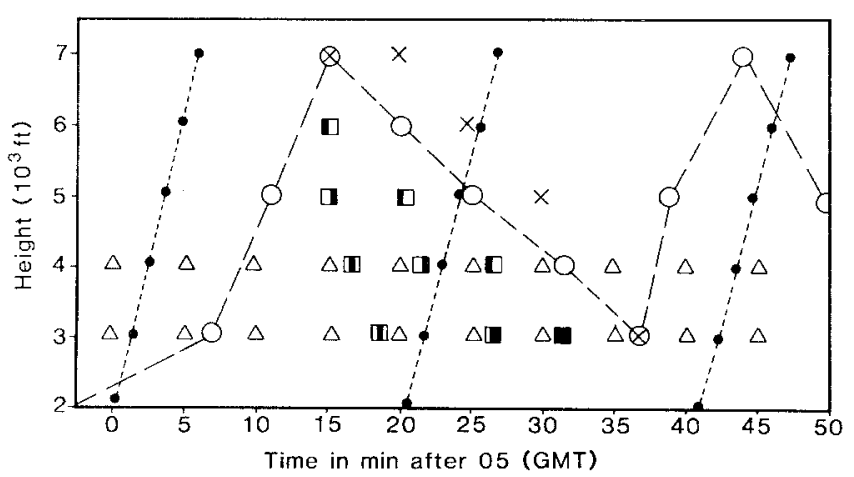

Fig. 2. Time-height cross-section showing the operations during the comparison experiment at Oberpfaffenhofen on 27 June 1986. The indications are as follows: sonde (dot), Falcon (circle), Queenair (cross), LDA (triangle), and the motorized sailplanes (square). The various motorized sailplanes are indicated as follows: $\square \mathrm{M} 1, \square \mathrm{M} 2$, and $\square \mathrm{M} 3$ reference distance chosen for the comparison is defined by the runway of the airport. The length of the runway is $2000 \mathrm{~m}$. The launching position of the radiosondes and the location of the LDA are $300 \mathrm{~m}$ from the airfield. Starting at 0500 GMT three radiosondes were launched 20 minutes apart. During the 40 minutes of the sonde flights the aircraft flew at between 3000 and $7000 \mathrm{ft}$ MSL several times with vertical spacing of $1000 \mathrm{ft}$ (Fig. 2). All the aircraft flew parallel to the runway at the same height as well as at different heights five minutes apart. The aircraft needed different times to fly along the runway: $20 \mathrm{~s}$ (Falcon), $30 \mathrm{~s}$ (Queenair) and $40 \mathrm{~s}$ (motorized sailplanes). The sonde took about 5 minutes to reach the height of $7000 \mathrm{ft}$. Due to the synoptic situation, there was a surface flow from the east at about $5 \mathrm{~m} \mathrm{~s}^{-1}$ during the period of the experiment. This causes a westerly translation of the sondes of about $1.5 \mathrm{~km}$ while they rise to $7000 \mathrm{ft}$. This advection took place over a two-hour period, and the three soundings made by the radiosonde were similar. Therefore, assuming an east-west homogeneity, the radiosonde data are comparable to those of the aircraft and the LDA, taken above the runway.

The LDA data are derived by averaging the meteorological quantities over a volume. For the present experiment the LDA-cones are swept out by VAD scans at fixed elevation angles of $45^{\circ}$. With increasing height the layer for which the averaged wind is valid becomes thicker. Therefore, at $3000 \mathrm{ft}$ MSL the thickness is $100 \mathrm{~m}$ and at $4000 \mathrm{ft}$ MSL it is $300 \mathrm{~m}$.

\section{Data}

All aircraft data were gathered with a sampling rate of $1 \mathrm{~Hz}$ and were then averaged over the $2000 \mathrm{~m}$ length of the runway to obtain a reference value for the comparison. Depending on the speed there are 20,30, and 40 data points from the Falcon, Queenair and the motorized sailplanes, respectively. In all cases the data along the reference distance were constant or the $r m s$-difference was two order of magnitude smaller than the mean value.

The purpose of the comparison experiment is to determine the differences between the various measurement systems. To simplify matters, the data taken by the sonsors of the Falcon aircraft are considered to be the standard against which 
the other data are to be compared. This is justified by the results of the ALPEX aircraft comparison experiment, which showed the high quality of the data from the Falcon (Fimpel and Richner, 1986). Another reason is that the Falcon is able to measure all the necessary parameters such as wind, temperature and dew-point whereas the other systems are limited to measure only some of these parameters.

Because most flights are not exactly at the prescribed height level, the aircraft data have to be corrected in order to be comparable with the other data. This has been done using the vertical gradients of temperature, dew-point temperature and wind data from the radiosonde in order to convert all aircraft data at each level to the mean pressure at that level. The mean pressure was chosen to correspond to the $3000,4000,5000,6000$, or $7000 \mathrm{ft}$ height. The pressure was chosen as a reference because the sensors of the aircraft and the radiosonde take pressure data directly. The pressure is measured with an accuracy of between 0.25 mbar (Falcon) and 2.0 mbar (sonde, motorized sailplanes). With an average temperature change in height of about $0.1 \mathrm{~K} \mathrm{mbar}^{-1}$ an error of about $0.2 \mathrm{~K}$ must be considered additionally due to the necessary reduction procedure.

Table 2 shows the vertical gradients of temperature and dew-point temperature provided by the radiosonde. There is no strong vertical divergence of the temperature gradients, except above the $6000 \mathrm{ft}$ level. At this level the temperature decreases with increasing pressure, indicating an inversion which was present during the entire day (Fig. 1). The dew-point temperature gradients at $6000 \mathrm{ft}$ were very large due to this inversion. These gradients indicate that a comparison of data taken in layers where inversions are present, is somewhat

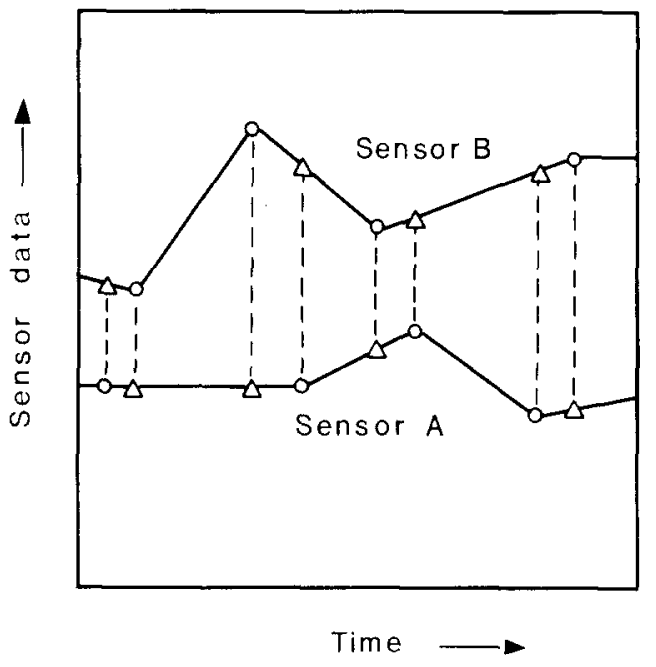

Fig. 3. Interpolation of two time series. Dots represents measured values, triangles indicate interpolated values

unreliable, because a slight deviation in height may drastically change the gradients. The vertical gradients of the wind were very small and therefore do not need to be considered further.

All time series were then combined for the comparison, the data from each sensor being linearly interpolated with respect to time, thus giving additional values at the time when other sensors in the comparison have values (Fig. 3). The vertical gradients were interpolated using an analogous procedure.

\section{Results}

\subsection{Temperature}

Figure 4 (left) shows the temperature data taken by the various systems at various times and heights. All differences are in the range of 1 to

Table 2. Vertical Gradients of Temperature (left) and Dew-Point Temperature (right) as Derived from the Radiosonde Profiles

\begin{tabular}{|c|c|c|c|c|c|c|}
\hline Height (ft) & \multicolumn{4}{|c|}{$\partial T / \partial p\left(10^{-2} \mathrm{~K} \mathrm{mbar}^{-1}\right)$} & \multicolumn{2}{|c|}{$\partial T_{D} / \partial p\left(10^{-2} \mathrm{~K}\right.$ mbar $\left.^{-1}\right)$} \\
\hline \multicolumn{7}{|c|}{ Time (min) after $0500 \mathrm{GMT}$} \\
\hline & $00-05$ & $20-25$ & $40-45$ & $00-05$ & $20-25$ & $40-45$ \\
\hline 3000 & 8.3 & 7.1 & 6.1 & 8.3 & -5.7 & -1.4 \\
\hline 4000 & 2.0 & 8.3 & 9.9 & -8.0 & 2.4 & 1.0 \\
\hline 5000 & 8.4 & 8.3 & 8.3 & -3.3 & 2.4 & 1.0 \\
\hline 6000 & 5.4 & -5.7 & -16.0 & 9.2 & 91.4 & 98.0 \\
\hline 7000 & 0.8 & -1.9 & 6.0 & -4.2 & 23.8 & 9.2 \\
\hline
\end{tabular}




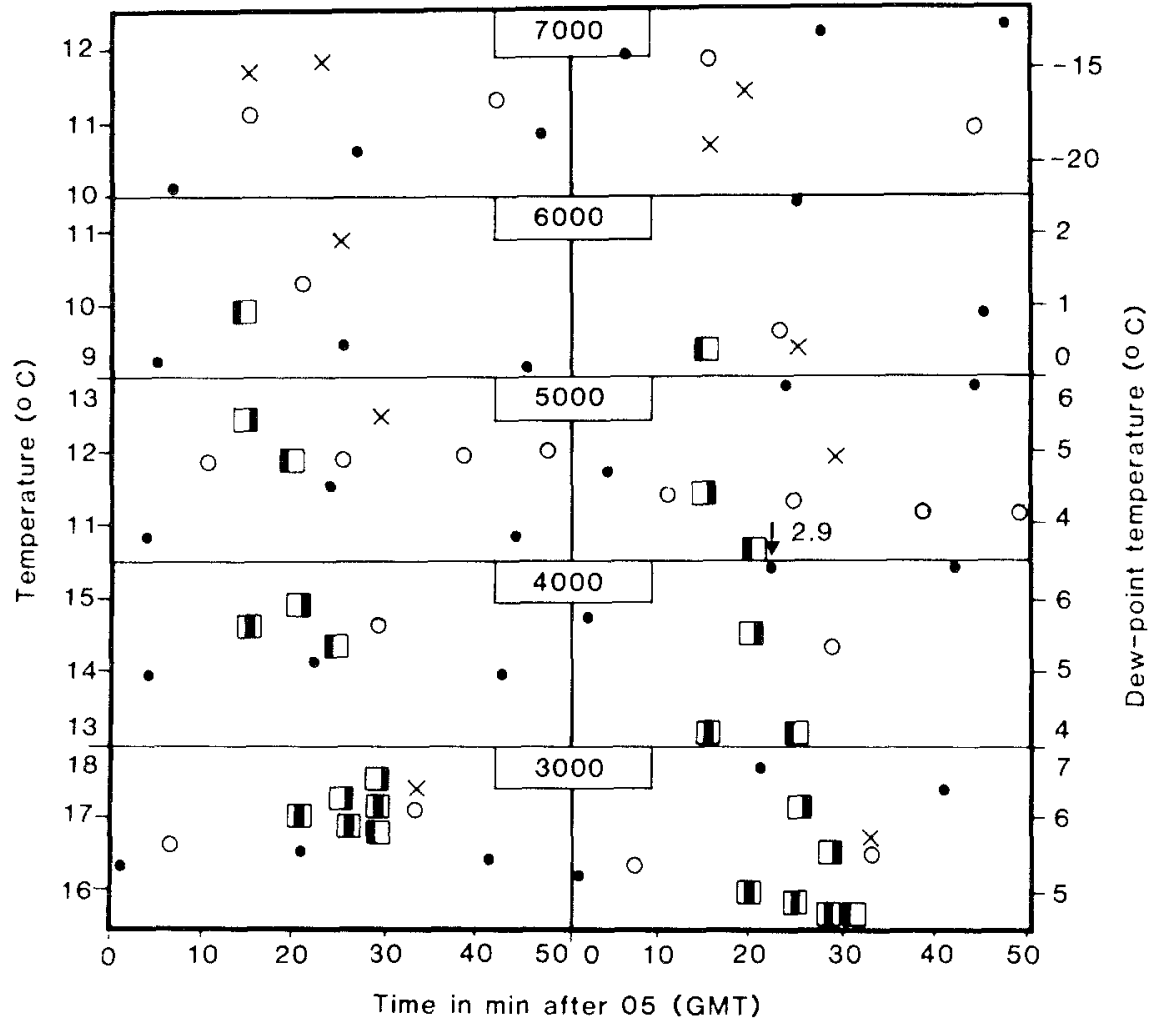

Fig. 4. Temperatures (left) and dewpoint temperatures (right) taken by various measurement systems. For symbols see Fig. 2. The heights are given in $\mathrm{ft}$

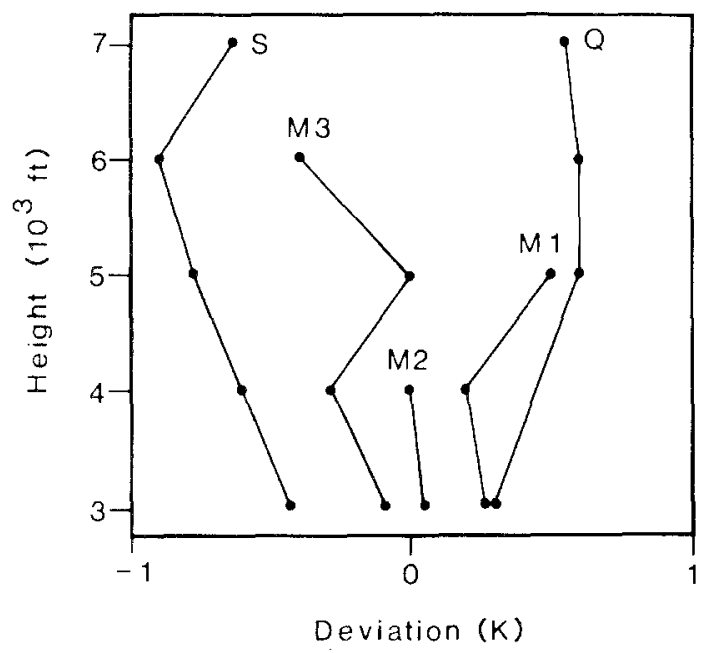

Fig. 5. Deviations of temperatures taken by the sensors of the sonde, Queenair and the motorized sailplanes from those taken by the Falcon-sensors. The deviations are defined by the difference values of the corresponding system minus the value of the Falcon-sensor. The letters S, A, M1, M2, and M 3 stand for the sensors of the sonde, the Queenair, motorized sailplane $\mathrm{M} 1, \mathrm{M} 2$, and $\mathrm{M} 3$, respectively

$2 \mathrm{~K}$. The mean differences of each flight level between the sensors of the Falcon and those of the other aircraft are given in Fig. 5. Compared to the data of the Falcon, those of the motorized sailplane M2 give almost identical results, those of the motorized sailplane M 3 are generally too low and those of motorized sailplane M 1 and the Queenair are too high. These differences increase with height. During ALPEX, a comparison between the sensors of the NCAR-Electra, NOAA$P 3$ and the DFVLR-Falcon resulted in mean differences (standard deviations) of the temperatures between $-0.3 \mathrm{~K}$ and $+0.6 \mathrm{~K}( \pm 0.1 \mathrm{~K})$ (Fimpel and Richner, 1986). Our results corroborate these differences indicating that the sensors of all aircraft measured the temperature reasonably well.

The differences between the Falcon- and the sonde-data indicate that the sondes generally take the temperature to be about $0.5 \mathrm{~K}$ lower than the sensor of the Falcon at all heights. The divergence of the temperature with increasing height is worth noting. To our knowledge, no comparisons have been made between the sondes used in this study and other radiosondes. However, a similar type to our GRAW-77Q sonde was compared with other sondes (Phillips and Richner, 1983). The result was that most sondes give temperatures that differ by about $1 \mathrm{~K}$.

Figure 6 (left) gives a summary of the results of all temperature measuring systems in terms of the deviations from the temperature sensors of the Falcon. The rms-differences are indicated by bars. 
Table 3. Mean Differences in Temperatures $(\Delta T)$ and Dew-Points $\left(\Delta T_{D}\right)$ Between the Radiosonde, Queenair and Motorized Sailplanes (M1, M2, M3) Temperature Measurements, and those of the Falcon. The [ ], $\sigma$ and "95\%" stand for the mean value, the standard deviation and the $95 \%$ significance level, respectively

\begin{tabular}{|c|c|c|c|c|c|c|}
\hline & \multicolumn{3}{|l|}{$\Delta T(\mathrm{~K})$} & \multicolumn{3}{|c|}{$\Delta T_{D}(\mathrm{~K})$} \\
\hline & $\overline{[]}$ & $\sigma$ & $95 \%$ & $\overline{[]}$ & $\sigma$ & $95 \%$ \\
\hline $\begin{array}{l}\text { Sonde } \\
\text { minus } \\
\text { Falcon }\end{array}$ & -0.66 & 0.74 & 0.40 & +1.57 & 1.88 & 1.02 \\
\hline $\begin{array}{l}\text { Queenair } \\
\text { minus } \\
\text { Falcon }\end{array}$ & +0.52 & 0.60 & 0.52 & -1.20 & 2.65 & 2.32 \\
\hline $\begin{array}{l}\text { M } 1 \\
\text { minus } \\
\text { Falcon }\end{array}$ & -0.33 & 0.40 & 0.39 & +0.25 & 0.44 & 0.43 \\
\hline $\begin{array}{l}\text { M2 } \\
\text { minus } \\
\text { Falcon }\end{array}$ & +0.03 & 0.10 & 0.10 & -0.88 & 1.07 & 1.05 \\
\hline $\begin{array}{l}\text { M3 } \\
\text { minus } \\
\text { Falcon }\end{array}$ & -0.20 & 0.29 & 0.29 & -0.93 & 1.21 & 1.19 \\
\hline
\end{tabular}

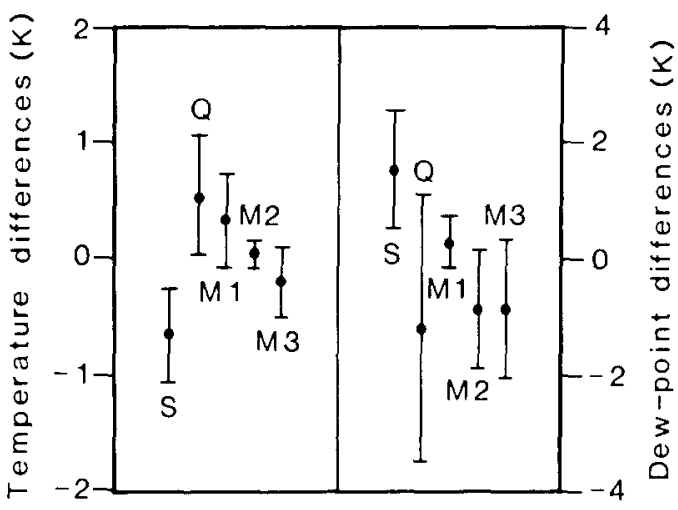

Fig. 6. Mean temperature differences (left) and dew-point temperature differences (right) between all systems. The differences are obtained by taking the corresponding value minus the values of the Falcon-sensor. The horizontal bars show the range of the corresponding $r m s$-difference. For abbreviations see Fig. 5

All aircraft sensor systems deviate in the range of $\pm 0.5 \mathrm{~K}$ from the Falcon system. Only the data of the sondes and the data of the Queenair have rmsdifferences larger than $0.5 \mathrm{~K}$. Table 3 gives the mean $r m s$-differences, the standard deviations and the $95 \%$ significance level. The magnitude of these mean differences are similar to the accuracies of the corresponding sensors (Table 1) which indicates that the data are of high quality.

\subsection{Humidity}

Phillips et al. (1980) pointed out that for all sondes, the relative humidity must be considered to be the least reliable of the radiosonde data. For the present intercomparison the dew-point temperature differences are in the range of $2 \mathrm{~K}$ for the lower levels, but in the $7000 \mathrm{ft}$ level this range increases up to $5 \mathrm{~K}$ (Fig. 4, right). The level-mean differences ar reasonable between the data of the Falcon sensors and those of the motorized sailplane M 1 up to $6000 \mathrm{ft}$ level (Fig. 7). The difference between the data of the Falcon and those of the Queenair is up to $6000 \mathrm{ft}$ very small, but increases rapidly up to $-3.3 \mathrm{~K}$ at $7000 \mathrm{ft}$. This is due to the fact that the response time of the TP 3-S is very large as soon as the dew-point differences become large which is the case for the presents event above $6000 \mathrm{ft}$ (Fig. 1). Therefore, the data taken by this sensor above the inversion are unreliable. The data from the sensors of the motorized sailplanes M 2 and $\mathrm{M} 3$ deviate more than $1 \mathrm{~K}$ from those of the Falcon system. The ALPEX comparison (Fimpel and Richner, 1986) showed mean differences (standard deviations) of the dew-points of $1.2 \mathrm{~K}$ $( \pm 2.9 \mathrm{~K})$.

The deviation of the sonde data from those of the Falcon $( \pm 1.0 \mathrm{~K})$ is reasonable up to $4000 \mathrm{ft}$, 


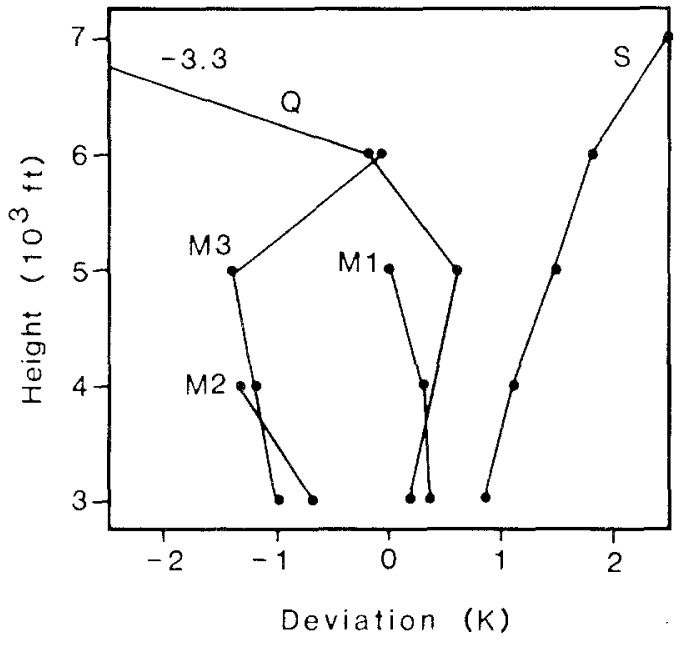

Fig. 7. Same as Fig. 5 but for the dew-points

but further up, the quality of the sondes data degrades (Fig. 7). The explanation for the present behaviour of the sonde-sensor is that the humidity is measured by a wet-bulb thermometer, which is not able to measure the temperature exactly once it drops below $0{ }^{\circ} \mathrm{C}$. Phillips and Richner (1983) reported that in terms of relative humidity a GRAW-type sonde showed deviations of up to $15 \%$ (max. height $5000 \mathrm{~m}$ ), again worsening with increasing height. This value is equivalent to a dew-point deviation of $2.1 \mathrm{~K}(3.5 \mathrm{~K})$ for a mean relative humidity of $50 \%(90 \%)$.

The overall quality of the humidity data are given in Fig. 6 (right), showing that all aircraft data deviate from the Falcon data in a range from $+0.5 \mathrm{~K}$ to $-2.0 \mathrm{~K}$, with $r m s$-differences of up to $0.5 \mathrm{~K}$ for the data of the motorized sailplanes and $1.0 \mathrm{~K}$ for the Queenair data. The corresponding standard deviations and the $95 \%$ significance levels are given in Table 2. In contrast to the temperature differences, the mean differences in dewpoints are slightly larger in magnitude than the accuracies of the corresponding sensors (Table 1). This corroborates the findings of Phillips et al. (1980) that humidity data provided by a radiosonde should be considered with caution.

\subsection{Wind}

The differences for both wind components between the Falcon-, the sondes- and the LDA-data are between 1 and $2 \mathrm{~m} \mathrm{~s}^{-1}$ (Fig. 8). The rms-differences (standard deviations) between the Falcon- and the sonde-data are $+0.3 \mathrm{~m} \mathrm{~s}^{-1}$ $\left(1.0 \mathrm{~m} \mathrm{~s}^{-1}\right)$ for the westerly wind and $-0.9 \mathrm{~m} \mathrm{~s}^{-1}$ $\left(1.7 \mathrm{~m} \mathrm{~s}^{-1}\right)$ for the southerly wind (Table 4). The ALPEX comparison (Fimpel and Richner, 1986)

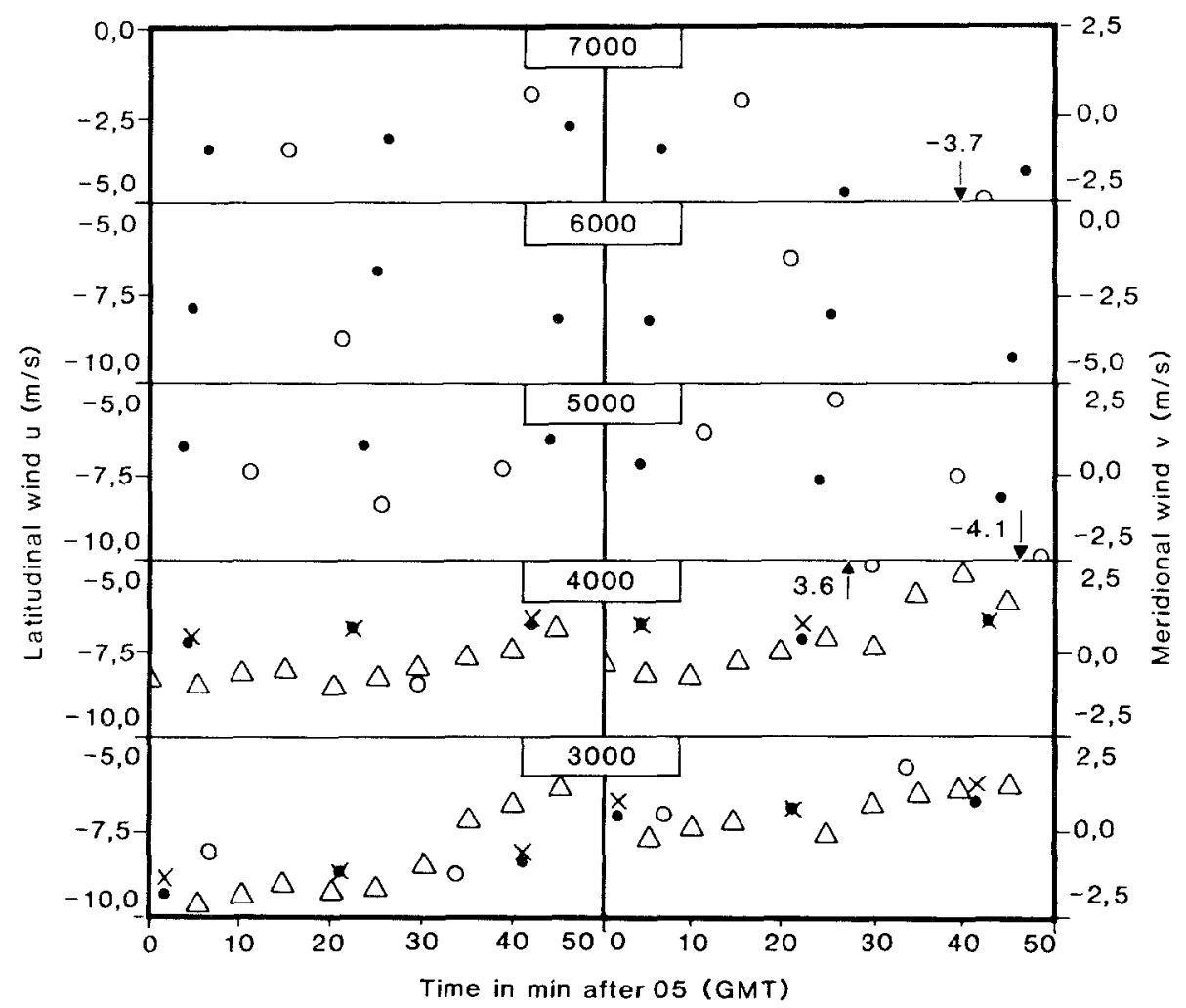

Fig. 8. Zonal wind (left) and meridional wind (right) taken by the sondes (dot), the Falcon (circle) and by the LDA (triangle). The crosses mark values from the sondes representing mean values over the same layer as was valid for the LDA measurements. The height is expressed in $\mathrm{ft}$ 
between several aircraft resulted in mean differences (standard deviations) of the westerly wind between $-0.6 \mathrm{~m} \mathrm{~s}^{-1}$ and $+1.0 \mathrm{~m} \mathrm{~s}^{-1}( \pm 0.4 \mathrm{~m}$ $\mathrm{s}^{-1}$, and of the southerly wind component between $\left.-0.9 \mathrm{~m} \mathrm{~s}^{-}\right)$and $+0.3 \mathrm{~m} \mathrm{~s}^{-1}\left( \pm 0.7 \mathrm{~m} \mathrm{~s}^{-1}\right)$. The magnitude of the $r m s$-differences are reasonably small, particularly, since even data of sondes of the same type may differ. Jasperson (1982) found a $r m s$-difference of $1.0 \mathrm{~m} \mathrm{~s}^{-1}$ between two pilot balloons launched simultaneously only $20 \mathrm{~m}$ apart, gathering data over altitudes from 0 to $5 \mathrm{~km}$.

In a previous study (Köpp et al., 1984) lowlevel winds from LDA and winds derived from balloon sondes were compared. They found average $r m s$-differences of $1.3 \mathrm{~m} \mathrm{~s}^{-1}$ for the magnitude and a $r m s$-difference of $12^{\circ}$ for direction when the LDA and the sonde profiles are compared. These values result in about $1.0 \mathrm{~m} \mathrm{~s}^{-1} \mathrm{rms}-$ difference for both wind components. They showed also that these differences are not a result of LDA errors because comparisons between LDA and a sonic anemometer showed a $r m s$-difference of $0.2 \mathrm{~m} \mathrm{~s}^{-1}$ for a single wind component. The rms-differences between the data of our LDA, those of the Falcon and those of the sondes were between $-0.71 \mathrm{~m} \mathrm{~s}^{-1}$ and $+0.63 \mathrm{~m} \mathrm{~s}^{-1}$ (Table 4). These values confirm that there is good agreement between the data of the Falcon, the sonde and the LDA wind measuring systems.

The wind field is not usually the same at all points of a full VAD scan because of atmospheric inhomogeneity, especially near the surface. Therefore, Fig. 8 gives also radiosonde data (crosses), representing the mean values over the same layer as is measured by the VAD scans. It is apparent that the deviations are small. However, these mean values are only vertical averages, thus the horizontal inhomogeneity must be small. This was also confirmed by the aircraft data showing standard deviations to be two order in magnitude smaller than the mean value along the reference path parallel to the runway.

\section{Conclusions}

Through an intercomparison experiment, as described in the present study, only the differences of the signals of the sensors of the various systems are obtained, but the absolute error or the accuracy can not be derived. Only when several systems are compared and one signal show significant deviations from the others, this could be an indication, that the sensor with the deviating signal is not working well. But also the contrary could be the case. In our experiment all differences, with one exception, are small, suggesting a good quality of the data. The exception is the humidity temperature measured by a wet-bulb thermometer in the sonde in case of temperatures close to and below freezing. In this case, these data are useless.

It is in general difficult to compare line-averaged data obtained from an aircraft along a horizontal flight path with radiosonde data taken along a vertical line and with quantities averaged over a volume using remote sensing techniques. The problems are kept small as soon as there are horizontal homogeneous atmospheric conditions,

Table 4. Mean Differences in Horizontal Wind Components Between the Radiosonde, Falcon and LDA Wind Measurements. For Notation see Table 3

\begin{tabular}{|c|c|c|c|c|c|c|}
\hline & \multicolumn{3}{|c|}{$u\left(\mathrm{~m} \mathrm{~s}^{-1}\right)$} & \multicolumn{3}{|c|}{$v\left(\mathrm{~m} \mathrm{~s}^{-1}\right)$} \\
\hline & $\overline{[]}$ & $\sigma$ & $95 \%$ & $\overline{[}]$ & $\sigma$ & $95 \%$ \\
\hline $\begin{array}{l}\text { Sonde } \\
\text { minus } \\
\text { Falcon }\end{array}$ & +0.34 & 1.01 & 0.55 & -0.92 & 1.70 & 0.92 \\
\hline $\begin{array}{l}\text { Sonde } \\
\text { minus } \\
\text { LDA }\end{array}$ & -0.63 & 1.13 & 0.47 & +0.36 & 0.80 & 0.33 \\
\hline $\begin{array}{l}\text { LDA } \\
\text { minus } \\
\text { Falcon }\end{array}$ & -0.34 & 1.04 & 0.77 & -0.71 & 0.89 & 0.66 \\
\hline
\end{tabular}


if the averaging length over the flight leg is short enough and if the measurements are taken during a reasonably short period of time. All these conditions were fulfilled during the present intercomparison experiment.

The results of the intercomparison experiment show that the data have in general small $r m s-$ differences. In particular: the temperature deviates between $-0.7 \mathrm{~K}$ and $+0.5 \mathrm{~K}$ between all measurement systems; the dew-point temperature deviates between $-1.2 \mathrm{~K}$ and $+1.6 \mathrm{~K}$; and the differences in the magnitude of the horizontal wind components are smaller than $1.0 \mathrm{~m} / \mathrm{s}$. The magnitude of most rms-differences are similar to the accuracies of the corresponding sensors, which indicates that the data are of high quality. Additionally, most of the observed and expected changes in magnitude of the meteorological signals in frontal systems are about one order in magnitude greater than the above $r m s$-differences. Therefore, coordinated measurements using ground-based systems, aircraft and radiosondes can produce data of high quality, particularly in meteorological conditions such as cold fronts.

\section{Acknowledgements}

The scientific observers on board of the aircraft were $\mathrm{S}$. Buhl, Dr. Th. Jank, W. Peters, F. Rösler and H. Willeke. They also carried out the data processing. F. Adler, K. Aigner, H. Löbel, and H. G. Rüba launched the radiosondes. The radartracking of the sondes was done by X. Kalteis and his colleagues.

\section{References}

Fimpel, H., Richner, H., 1986: Results of the ALPEX aircraft intercomparison on 19 April 1982: In: Scientific Results of the Alpine Experiment (ALPEX). GARP Publ. Series, 27, 85-94.

Fink, C., Schöllman, E., Kölbl, A., 1980: TDFS low-level radiosonde system. In: Kaimal et al. (Eds.): Low-Level
Intercomparison Experiment (BLIE). Instruments and $\mathrm{Ob}-$ serving Methods, Rep. No.3, published by the WMO, Geneva, 100-104.

Hauf, Th., Walter, H., Walk, O., 1988: Ein Vergleich von Flugzeug- und Radiosondenmessungen während MESOKLIP. Meteor. Rdsch. (in press).

Jasperson, W. H., 1982: Mesoscale time and space variability. J. Appl. Meteor., 21, 831-839.

Jochum, A. M., Reinhardt, M. E., Willeke, H., 1984: Die drei Motorsegler der DFVLR - ein meteorologisches Meßsystem zur Untersuchung der atmosphärischen Grenzschicht. DFVLR-Note 84-50 (obtainable from Institute of Atmospheric Physics, DFVLR, 8031 Oberpfaffenhofen).

Kaimal, J. D., Baynton, H. W., Gaynor, J. E., (Eds.), 1980: Low-Level Intercomparison Experiment. Boulder, Colorado, USA, Aug.-Sept. 1979 (BLIE). Instruments and Observing Methods, Rep. No. 3, published by the WMO, Geneva, pp. 191.

Köpp, F., Schwiesow, R. L., Werner, Ch., 1984: Remote measurements of boundary-layer wind profiles using a CW-Doppler-Lidar. J. Climate Appl. Meteor., 23, 148154.

Meischner, P., 1985: Nutzerhandbuch für das Falcon-System. DFVLR-Note 85-08 (obtainable from Institute of Atmospheric Physics, DVFLR, 8031 Oberpfaffenhofen).

Paffrath, D., 1985: DVFLR-Meßsystem zur Erfassung der räumlichen Verteilung von Umweltparametern in der Atmosphäre mit mobilen Meßträgern. DVFLR-Note 85-09 (obtainable from Institute of Atmospheric Physics, DFVLR, 8031 Oberpfaffenhofen).

Phillips, P. D., Richner, H., 1983: SONDEX-the ALPEX radiosonde intercomparison. Fifth Lymp. on Meteor. Obs. and Instrumentations. April 11-15, 1983, Toronto, Ont., Canada. Published by the American Meteorological Society, Boston, Mass., 141-147.

Phillips, P. D., Richner, H., Joos, J., Ohmura, A., 1980: ASOND-78: An intercomparison of Väisälä, VIZ and Swiss radiosondes. PAGEOPH., 119, 259-277.

Schwiesow, R. L., Köpp, F., Werner, Ch., 1985: Comparison of CW-Lidar-measured wind values obtained by full conical scan, conical sector scan and two point techniques. J. Atmos. and Oceanic. Techn., 2, 3-14.

Authors' addresses: Dr. Klaus P. Hoinka and H. P. Fimpel, Institute of Atmospheric Physics; F. Köpp, Institute for Optoelectronics, DFVLR, D-8031 Oberpfaffenhofen, Federal Republic of Germany. 